\title{
Jejunouterine fistula: a case report
}

\author{
M. E. C. McFarlane • J. M. Plummer • T. Remy • \\ L. Christie • D. Laws • H. Richards • T. Cherrie • \\ R. Edwards $\cdot$ C. Coward
}

Received: 19 July 2007 / Accepted: 15 October 2007 / Published online: 15 November 2007

(C) Springer-Verlag 2007

\begin{abstract}
Jejunouterine fistula is a rare type of fistulous communication between the small intestine and the genital tract. This fistula may result from pelvic tumours, obstetric or surgical intervention and inflammatory disease. Crosssectional imaging modalities, including ultrasonography, magnetic resonance imaging (MRI) and computed tomography (CT), are useful investigations which may demonstrate the site and track of the fistula. Traditional contrast investigations, including hysterosalpingography, are also helpful. Surgical resection of the fistula with primary anastomosis is curative in the majority of cases.
\end{abstract}

Keywords Jejunouterine fistula $\cdot$ Enterouterine fistula

\section{Introduction}

We present the case of a patient who developed a jejunouterine fistula following curettage performed for severe postpartum haemorrhage. The diagnosis was based on a clinical evaluation that documented the loss of intestinal contents per vaginam and an enterouterine fistula

\footnotetext{
M. E. C. McFarlane · J. M. Plummer $\cdot$ T. Remy $\cdot$ L. Christie $\cdot$ D. Laws $\cdot$ H. Richards $\cdot$ T. Cherrie $\cdot$ R. Edwards $\cdot$ C. Coward Department of Surgery, Radiology,

Anaesthetics and Intensive Care, Department of Obstetrics and Gynaecology, University of the West Indies,

Mona, Jamaica

M. E. C. McFarlane $(\bowtie)$

P.O. Box 110, Mona Kingston 7, Jamaica

e-mail: michaelm500@yahoo.com
}

demonstrated by hysterosalpingography. A brief review of this unusual but interesting problem then follows.

\section{Case report}

A 25-year-old woman with no previous medical illnesses was admitted to hospital and had a vaginal delivery of a fullterm infant. This was complicated by massive postpartum haemorrhage, which required treatment with laparotomy and bilateral uterine artery ligation.

Despite further medication, she continued to have significant vaginal bleeding up to 10 weeks after discharge. She was diagnosed with retained products of conception and was treated with dilatation and curettage $(\mathrm{D} \& \mathrm{C})$. For three days post-D\&C, she experienced vomiting and "chills," which subsequently resolved. Two weeks later, she presented with discharge of bile-stained fluid and semidigested food particles per vaginam. A hysterosalpingogram was performed and showed an enterouterine fistula (Fig. 1). Further imaging excluded the presence of intraperitoneal fluid collections.

A laparotomy was performed and it identified a fistula between the posterior uterine fundus and a loop of proximal jejunum. The uterus was necrotic and indurated. Five centimetres of involved jejunum, including the fistula, was resected and a primary jejunojejunal anastomosis performed. Due to extensive erosion of the endometrium and necrosis of the myometrium, a subtotal hysterectomy was performed. The histopathology confirmed the presence of a fistula involving the uterus and jejunum. There was no other pathological lesion identified. Her postoperative course was uneventful and she was discharged five days later. 


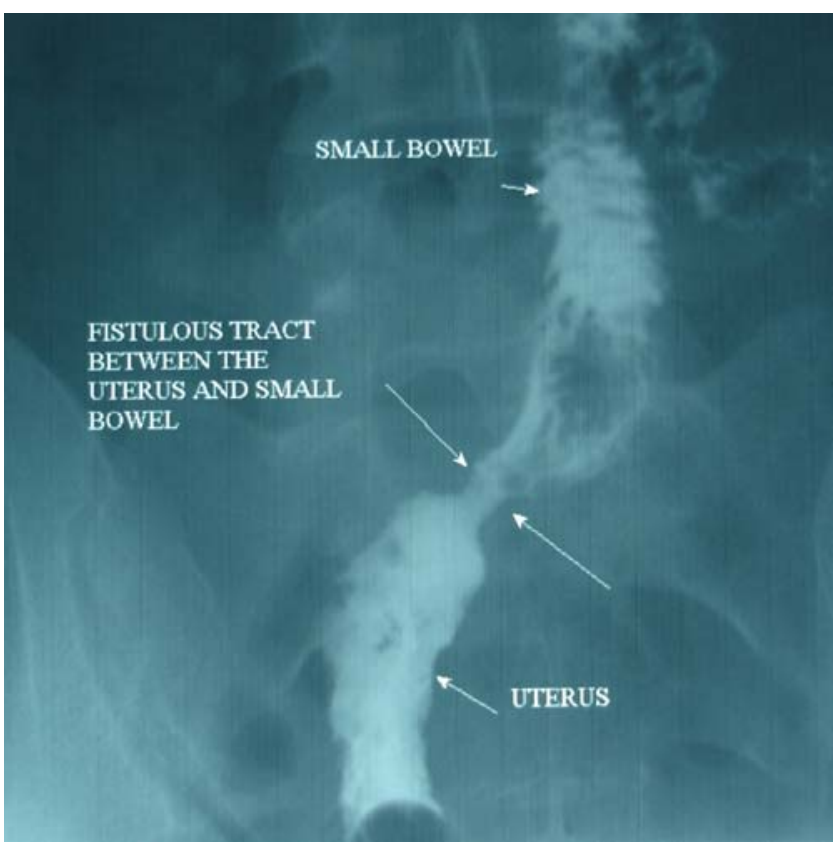

Fig. 1 Hysterosalpingogram showing fistulous communication between the uterus and jejunum

\section{Discussion}

Fistulous communication between the gastrointestinal tract and the uterus is rare. The fistula is usually found between the fundus of the uterus and loops of small bowel or sigmoid colon. Fistulas have been described following obstetric and oncological pathology, and rarely following D\&C procedures [1].

A variety of fistulas involving the genital tract and gastrointestinal system have been reported. Fistulas have been described involving the vagina, fallopian tubes and rarely the uterus [2]. Few reports exist of fistulous communication between the uterus and jejunum [3, 4]. The fistula in the case reported most likely resulted from perforation of the uterus at the time of the dilatation and curettage with involvement of the bowel. The differential diagnosis of a morbidly adherent placenta or gestational trophoblastic disease was also entertained in this case, though it was not confirmed by histopathology. In a recent review, uterine perforation was found to occur in about $0.4 \%$ of $\mathrm{D} \& \mathrm{C}$ procedures for second-trimester abortions [5]. Amarin and Badria [6] described an incidence of $0.2 \%$ in a series of 11,914 women when D\&C was performed for retained products of conception. Darney et al. [7] described a series of 15 cases of post-D\&C perforations; two-thirds had bowel injuries, two required bowel resection and colostomy, one patient underwent a resection and immediate reanastomosis and two required hysterectomy. In Darney et al.'s series, 12 of the 15 cases underwent laparotomy within $24 \mathrm{~h}$ of the initial perforation. Although D\&C procedures are associated with low risk, inadvertent uterine perforation is a serious complication that is frequently unrecognised, making its true incidence unknown [6].

Other common aetiologies implicated in the genesis of these fistulas include chronic inflammatory bowel disease, e.g. Crohn's disease and complications of diverticulitis, neoplasms, congenital diseases and iatrogenic trauma $[2,8]$. A review by Martin et al. [1] in 1956 identified only 80 cases of enterouterine fistula. Few additional case reports have been documented since then.

The majority of the cases reported by Martin et al. [1] followed obstetric injury in 42 cases. Seventeen cases were associated with inflammatory disease, diverticulitis and appendicitis, nine cases following malignancy and 12 cases were associated with trauma, including iatrogenic surgical complications and criminal abortion. A 15-year review of cases at the Mayo Clinic revealed that gynaecologic and obstetric procedures and operations were the major cause of genital tract fistulas [9].

In cases where malignancy is a cause of enterouterine fistula, endometrial carcinoma is the most common [1]. Other case reports have implicated sigmoid, rectal and ovarian carcinoma $[8,10]$. Diverticulitis has been shown to be a rare cause of fistula involving the sigmoid colon and few cases have been described [11]. The diagnosis relies on a high index of suspicion and careful physical examination. Enterouterine fistula usually present with loss of gastrointestinal contents from the vagina. Pelvic examination reveals an intact vaginal wall, with intestinal contents arising from the cervical os, as was found in the case presented here. Canulating the cervical os allows the measurement of the output, which will determine whether it is a high- or low-output fistula. Hysterosalpingography is useful in outlining the characteristics of the fistula and may be the investigation of choice in the majority of cases. Cross-sectional imaging with computed tomography (CT) and magnetic resonance imaging (MRI) may be necessary to identify extraluminal disease or abscesses that may be missed with contrast studies [12]. The advantage of modern CT systems and MRI to demonstrate subtleties in the anatomy of the fistula, including the course of the track, allow these investigations to be used to outline ambiguous pathology [9]. MRI may be the investigation of choice in difficult cases, since it provides images of exceptional clarity, which can be obtained in the plane of the fistula, outlining the fistulous track and any associated extraluminal disease.

Early diagnosis based on a suspicion of inadvertent uterine perforation and prompt intervention will prevent significant morbidity. The risk of perforation can be reduced by adopting a careful and meticulous technique 
during D\&C. Treatment options depend on the nature of the fistula, the nutritional status of the patient and the presence of associated disease. Surgical therapy is usually advocated in good-risk patients and includes resection of the involved bowel with primary anastomosis and closure of the uterine defect. Rarely, temporary ileostomy with prolonged nutritional support may be required $[13,14]$.

\section{References}

1. Martin DH, Hixson CH, Wislon EC Jr (1956) Enterouterine fistula; review; report of an unusual case. Obstet Gynecol 7 (4):466-469

2. Trastour C, Rahili A, d'Angelo L, Bafghi A, Benizri E, Bongain A, Benchimol D (2006) Benign enterogenital fistulas arising from the digestive tract: three cases. J Gynecol Obstet Biol Reprod (Paris) 35(7):720-724

3. Singh RB, Pavithran NM, Parameswaran RM, Sangwan K (2005) Chronic jejuno-uterine fistula: an unusual cause for recurrent second trimester abortions. Aust N Z J Obstet Gynaecol 45 (6):533-534

4. Vohra PA, Kumar Y, Raniga S, Vaidya V, Verma S, Mehta C (2005) A case of jejunouterine fistula. Indian J Radiol Imag 15 (4):427-428
5. Peterson WF, Berry FN, Grace MR, Gulbranson CL (1983) Second-trimester abortion by dilatation and evacuation: an analysis of 11,747 cases. Obstet Gynecol 62(2):185-190

6. Amarin ZO, Badria LF (2005) A survey of uterine perforation following dilatation and curettage or evacuation of retained products of conception. Arch Gynecol Obstet 271(3):203-206

7. Darney PD, Atkinson E, Hirabayashi K (1990) Uterine perforation during second-trimester abortion by cervical dilation and instrumental extraction: a review of 15 cases. Obstet Gynecol 75(3 Pt 1):441-444

8. Eichbaum M, Schneeweiss A, Harms W, Schemmer P, Sohn C (2006) Ileouterine fistula after primary treatment of advanced endometrial cancer. Lancet Oncol 7(5):442

9. Lee RA, Symmonds RE, Williams TJ (1988) Current status of genitourinary fistula. Obstet Gynecol 72:313-319

10. Hession P, Mannion RA, Finan P, Chalmers AG (1997) Imaging appearances of ileouterine fistula complicating recurrent adenocarcinoma of the rectum. Br J Radiol 70(832):415-417

11. Huettner PC, Finkler NJ, Welch WR (1992) Colouterine fistula complicating diverticulitis: charcoal challenge test aids in diagnosis. Obstet Gynecol 80(3 Pt 2):550-552

12. Yu NC, Raman SS, Patel M, Barbaric Z (2004) Fistulas of the genitourinary tract: a radiologic review. Radiographics 24 (5):1331-1352

13. Lloyd DA, Gabe SM, Windsor AC (2006) Nutrition and management of enterocutaneous fistula. Br J Surg 93(9):1045-1055

14. Hjern F, Goldberg SM, Johansson C, Parker SC, Mellgren A (2007) Management of diverticular fistulae to the female genital tract. Colorectal Dis 9(5):438-442 